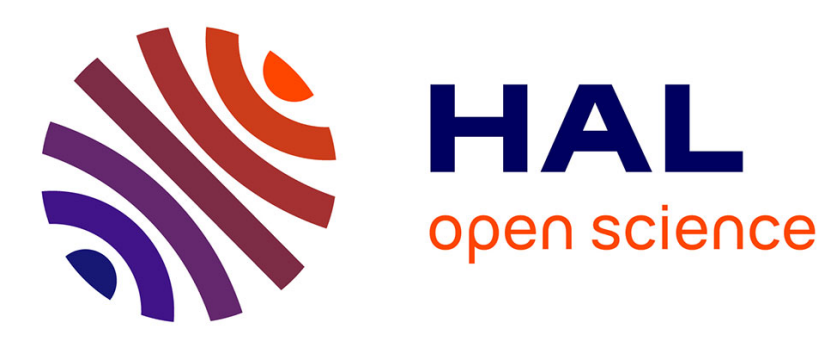

\title{
A lattice model to simulate ice-structure interaction
}

\author{
Olivier Dorival, Andrei Metrikine, Angelo Simone
}

\section{To cite this version:}

Olivier Dorival, Andrei Metrikine, Angelo Simone. A lattice model to simulate ice-structure interaction. ASME 2008 27th International Conference on Offshore Mechanics and Arctic Engineering, Jun 2008, Estoril, Portugal. pp.989-996, 10.1115/OMAE2008-57918 . hal-01023408

\section{HAL Id: hal-01023408 https://hal.science/hal-01023408}

Submitted on 16 Jul 2014

HAL is a multi-disciplinary open access archive for the deposit and dissemination of scientific research documents, whether they are published or not. The documents may come from teaching and research institutions in France or abroad, or from public or private research centers.
L'archive ouverte pluridisciplinaire HAL, est destinée au dépôt et à la diffusion de documents scientifiques de niveau recherche, publiés ou non, émanant des établissements d'enseignement et de recherche français ou étrangers, des laboratoires publics ou privés. 


\title{
A lattice model to simulate ice-structure interaction
}

\author{
O. Dorival, A. V. Metrikine, A. Simone \\ Department of Structural Mechanics \\ Faculty of Civil Engineering and Geosciences \\ Delft University of Technology \\ P. O. Box 5048, 2600 GA Delft, Netherlands
}

\begin{abstract}
The interaction between ice sheets and offshore structures is of key importance in the design of offshore platforms in the Arctic. Unfortunately, due to the complexity of ice material the use of small-scale experiments is problematic if one aims at drawing some conclusions about the forces exerted on large-scale structures such as oil rigs.

As a preliminary work this paper proposes a discrete numerical model to investigate the interaction between an ice sheet and a rigid structure. The behavior of ice is modelled by a two dimensional lattice model, in which inhomogeneity and possible failure of ice are incorporated. According to the numerical results such a model seems able to capture the main trends involved in ice sheets cracking. This is an essential step towards predicting interaction forces between ice and structure.
\end{abstract}

\section{INTRODUCTION}

The prediction of the forces exerted by ice sheets on oil rigs is of great interest for designers of offshore structures. Over the last decades several experiments have been performed in order to understand the ice load on the structures. Such experiments fall into two categories: large-scale tests to quantify realistic ice loads $[1,2,3,4]$, and medium or small-scale experiments to understand the material behavior of ice under compression $[5,6,7,8]$. The loads observed in the small-scale experiments can not be scaled straightforwardly to predict the ice loads on offshore structures [9]. The reason for that is an extremely inhomogeneous character of ice already at the meso-level due to the existence of very weak clusters and meso-cracks in the ice sheets.

A number of studies have employed empirical models to predict ice loads [10]. The drawback of such an approach is that it can not capture the physical mechanism of ice failure at the material level. To capture this mechanism, a model of ice should account for the material and geometrical inhomogeneity of ice, 
as well as the non-deterministic nature of ice parameters [11]. The material inhomogeneity should represent variation of the elastic and inertial properties, as well as that of the strength. The geometrical inhomogeneity represents the fact that all clusters in ice are of different sizes and different orientations just as in the ice material. Finally the model should be analyzed statistically. As the distribution of material properties and weaknesses vary from one ice sheet to another, the ice loads should be predicted in a statistical sense [12].

The above requirements can be met by introducing a lattice model of ice. The lattice models are known to be well-suited to reproduce the deformation and failure of materials such as concrete and soil, which are inhomogeneous at the meso-scale, like ice. The lattice model presented in this contribution is composed of a two-dimensional network of ice clusters initially interconnected by linear spring-dashpot elements. The failure of ice material is accounted for by breakable elements: when an element is broken it is simply removed from the model. Interaction with the structure, as well as friction between the faces of meso-cracks in the ice bulk is taken into account using the Coulomb's law. An implicit time-stepping algorithm is used to solve for the lattice motion. The aim of this preliminary contribution is to show the capability of the model to capture a reasonable behavior of ice failure. However it is clear that further studies are necessary to tune the model parameters against actual small and large scale experiments.

The remainder of this paper is as follows. In the next section the lattice model including failure of elements and internal friction along crack faces is described. The treatment of friction in the contact area and the time algorithm are given in Section 3. Section 4 presents examples of computations carried out using this model and shows its capability to reproduce experimental results. Concluding remarks and perspective of this work are reported in Section 5.

\section{LATTICE MODEL OF A BREAKABLE ICE SHEET}

Among plenty of possible applications, lattice models are widely used in mechanics of strongly inhomogeneous media such as soil and concrete, especially when local failures are of importance $[13,14,15,16,17,18,19,20]$. Various lattice models were used to simulate ice-structure interaction in [21, 22]. In what follows we use a simple hexagonal network of axial spring-dashpot elements connecting each cluster of the ice sheet with its neighbours. Other type of elements like Euler-Bernoulli beams or Reissner beams, involving rotational rigidity, are often chosen to model a Cosserat continuum. We have chosen for the network of purely axial elements because it is capable of describing all major macro-parameters of ice (provided that the network is inhomogeneous) and includes a relatively small number of the micro-parameters. 


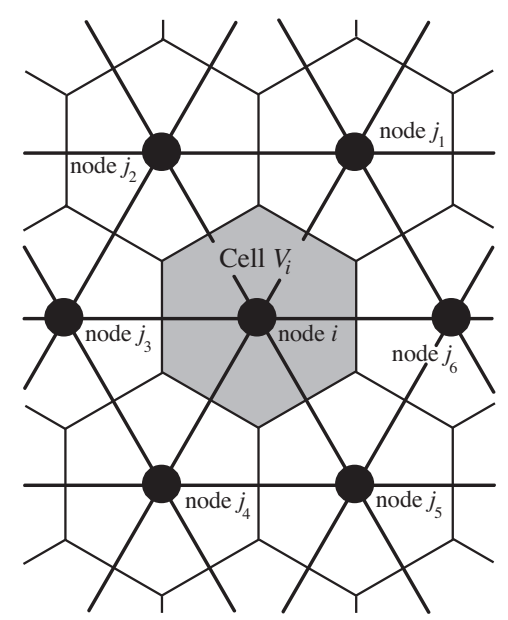

Figure 1: TRIANGULAR LATTICE MESH.

\subsection{Basic equations for the hexagonal lattice}

We first consider a regular hexagonal lattice shown in Figure 1. The ice sheet is modelled by an assembly of hexagonal particles, each of them represented by a lumped mass at its center. A particle is connected to a neighbour $j$ by an axial spring-dashpot element. The derivation of the lattice properties is done by assuming equivalence of the energy of the lattice with that of the corresponding continuum under the plain-strain assumptions:

$$
\begin{aligned}
\frac{1}{2} \int_{V_{i}} \sigma \varepsilon d V & =\frac{1}{2} \sum_{j} \tilde{k}_{i j} \Delta \tilde{l}_{i j}{ }^{2}, \\
\frac{1}{2} \int_{V_{i}} \rho \dot{\mathbf{x}}^{2} d V & =\frac{1}{2} m_{i} \dot{\mathbf{x}}_{i}^{2},
\end{aligned}
$$

with $\tilde{k}_{i j}$ and $\Delta \tilde{l}_{i j}$ denoting the stiffness and the elongation of the half-element $i j, m_{i}$ being the mass of node $i$ and $\rho$ and $V_{i}$ being the density and the volume of the cell $i$. In the case where all springs have the same stiffness $k$, one finds the following relations between the continuum (macro) and lattice (micro) parameters:

$$
E=\frac{3 \sqrt{3} k}{4 h}, \quad \nu=\frac{1}{4}, \quad \rho V_{i}=m_{i} .
$$

The dynamic equilibrium of a cell $i$ subjected to external forces $\mathbf{f}_{i}{ }^{\text {ext }}$ is given by

$$
m_{i} \ddot{\mathbf{x}}_{i}=\mathbf{f}_{i}^{i n t}(\mathbf{x}, \dot{\mathbf{x}})+\mathbf{f}_{i}^{e x t}(t),
$$

where the internal force vector $\mathbf{f}_{i}^{i n t}$ contains the forces from the spring-dashpots 


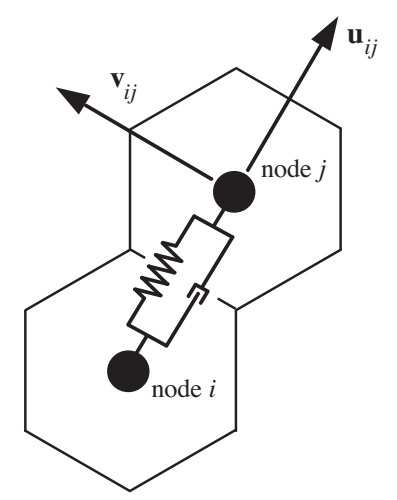

Figure 2: THE SPRING-DASHPOT ELEMENT LOCAL COORDINATES.

elements connecting cell $i$ and its neighbours $j$ :

$$
\mathbf{f}_{i}^{i n t}=\sum_{j} k_{i j} \Delta l_{i j} \mathbf{u}_{i j}+\sum_{j} c_{i j} \Delta v_{i j} \mathbf{u}_{i j},
$$

with $\mathbf{u}_{i j}$ and $\mathbf{v}_{i j}$ being the unit (normal and tangential, respectively) vectors defining the local coordinates of the element, see Figure 2. $k_{i j}$ and $c_{i j}$ denote the stiffness and the damping coefficient of the element $i j$, respectively. $\Delta l_{i j}$ and $\Delta v_{i j}$ stands for the elongation of the element and its derivative with respect to time.

By assembling Equation (4) for each cluster and by expressing $\Delta l$ and $\Delta v$ by means of the locations $\mathbf{X}$ and velocities $\dot{\mathbf{X}}$ we obtain the following matricial form of the dynamic equilibrium:

$$
\mathbf{M} \ddot{\mathbf{X}}=\mathbf{F}^{e x t}(t)+\mathbf{F}^{0}(\mathbf{X})-\mathbf{K}(\mathbf{X}) \mathbf{X}-\mathbf{C}(\mathbf{X}) \dot{\mathbf{X}},
$$

with $\mathbf{M}, \mathbf{K}, \mathbf{C}$ denoting the mass matrix, stiffness matrix and damping matrix respectively. $\mathbf{F}^{\text {ext }}$ is the assembly of external forces $\mathbf{f}_{i}^{\text {ext }} \cdot \mathbf{F}^{0}$ stands for the constant term due to the initial length of springs in Equation (5). Note that $\mathbf{K}$, $\mathbf{C}$ and $\mathbf{F}^{0}$ depend on the current configuration which introduces geometrical nonlinearities due to large displacements in the problem. Once initial conditions and boundary conditions are given, Equation (6) must be solved in the time domain.

\subsection{Failure of elements and friction between crack-lips}

The failure criterion is described in terms of elongation of each element connecting node $i$ and node $j$ :

$$
\text { if } \quad\left|l_{i j}-l_{i j}^{0}\right|>\Delta l_{i j}^{l i m}, \quad \text { then Element ij breaks. }
$$


Computationally speaking an element which is broken at time $t$ is simply removed from the model for following time steps. A crack is represented by several elements broken along a curve.

To account for possible closure of a crack the model involves interaction between nodes which are not yet connected by an (initial) element in case they are close enough to interact with each other. In this case the internal force between these two nodes "coming into contact" is composed of a spring-dashpot element and a tangential friction element. The latter stands for the tangential friction existing between nodes $i$ and $j$ of two crack lips:

$$
\mathbf{f}_{i}^{\text {friction }}=\left(k_{i j} \Delta l_{i j}+c_{i j} \Delta v_{i j}\right) \mathbf{u}_{i j}+\alpha \mu\left|k_{i j} \Delta l_{i j}+c_{i j} \Delta v_{i j}\right| \mathbf{v}_{i j},
$$

where $\alpha$ gives the direction of the friction force: $\alpha=\operatorname{sign}\left(\left[\dot{\mathbf{x}}_{j}-\dot{\mathbf{x}}_{i}\right] \cdot \mathbf{v}_{i j}\right)$.

\subsection{Geometrical and material randomness}

To meet the requirements of inhomogeneity of ice material, some randomness has to be included in the model. Geometrical randomness is introduced by a random perturbation of the node location inside the cell. This turns the lattice into a non-regular one and Equation (3) can be modified considering the length of each spring.

Material inhomogeneity is introduced by a random distribution of lattice properties. Spring stiffnesses $k_{i j}$, dashpot coefficients $c_{i j}$ and maximal elongations $\Delta l_{i j}^{l i m}$ are chosen according to a random gaussian distribution.

At last some weak elements are introduced in the model. Due to its history an ice sheet contains several weak clusters who play a crucial role in initiation and propagation of the cracks. These weak clusters are responsible for decreasing the strength of the ice sheets compared to small-scale ice blocks. The weak clusters are modelled by decreasing drastically the maximal elongation of a number of elements.

\section{ALGORITHMIC ASPECTS}

\subsection{Contact conditions}

Let us consider interaction between the lattice and a rigid body. Let $\Gamma$ be the contact area, $\mathbf{n}$ the outward normal to $\Gamma$ and $\mathbf{t}$ the tangential vector. $\mathbf{u}$ represents the relative displacement between the node considered and the contact area while $\lambda$ stands for the contact force. Contact is modelled by means of the following unilateral contact equations:

$$
\begin{array}{rlr}
\mathbf{u} \cdot \mathbf{n} & \geq 0 \\
\lambda \cdot \mathbf{n} & \leq 0 & \text { (non penetration) }, \\
(\mathbf{u} \cdot \mathbf{n}) \cdot(\lambda \cdot \mathbf{n}) & =0 & \text { (unilateral contact) }, \\
& \text { (complementary condition) },
\end{array}
$$




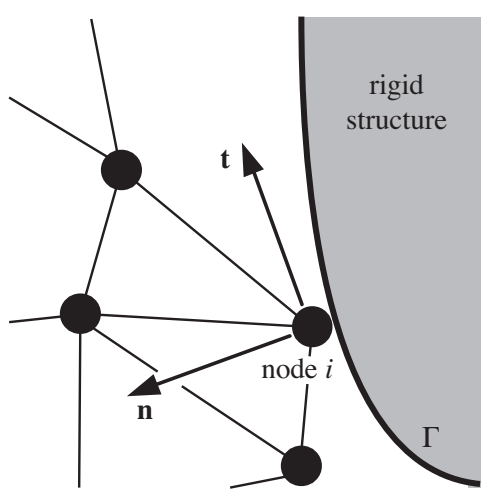

Figure 3: LOCAL COORDINATES FOR CONTACT.

and by Coulomb's friction law:

$$
\begin{array}{ll}
\text { if } \dot{\mathbf{u}}=0, & \text { then }|\lambda \cdot \mathbf{t}| \leq \mu|\lambda \cdot \mathbf{n}|, \\
\text { if } \dot{\mathbf{u}} \neq 0, & \text { then }|\lambda \cdot \mathbf{t}|=\mu|\lambda \cdot \mathbf{n}| \text { and }(\dot{\mathbf{u}} \cdot \mathbf{n}) \cdot(\lambda \cdot \mathbf{n}) \leq 0 .
\end{array}
$$

Several techniques have been developed to improve the treatment of contact problems $[23,24,25,26,27]$. The technique which is used here is based on an active set strategy that avoids computation of the Lagrange multipliers and the displacements at the same time, thus decreasing the size of the problem. Instead, the previous equations are replaced by the corresponding kinematic relations in Equation (6):

$$
\begin{aligned}
\ddot{\mathbf{u}} \cdot \mathbf{n} & =0 & & \text { (contact condition), } \\
\ddot{\mathbf{u}} \cdot \mathbf{t} & =0 & & \text { (sticking condition), } \\
m \ddot{\mathbf{u}} \cdot \mathbf{t} & =\left(\mathbf{f}^{\text {ext }}+\mathbf{f}^{\text {int }}\right) \cdot \mathbf{t} & & \text { (slipping condition). }
\end{aligned}
$$

Lagrange multipliers $\lambda$ are computed a posteriori after solving Equation (6) and active sets are then updated according to the frictional contact conditions $(8-12)$.

\subsection{Implicit Time Integration Scheme}

A time stepping algorithm is used to solve the problem in the time domain. Explicit integration schemes are well-known to be only conditionally stable and therefore the time step $\Delta t$ has to be very small, leading to a very large number of time iterations. For that reason implicit schemes, yielding a larger time step, are usually chosen. One of such scheme is the Newmark scheme in which

$$
\begin{aligned}
& \mathbf{X}_{n+1}=\mathbf{X}_{n}+\Delta t \dot{\mathbf{X}}_{n}+\frac{\Delta t^{2}}{2}\left((1-2 \beta) \ddot{\mathbf{X}}_{n}+2 \beta \ddot{\mathbf{X}}_{n+1}\right), \\
& \dot{\mathbf{X}}_{n+1}=\dot{\mathbf{X}}_{n}+\Delta t\left((1-\gamma) \ddot{\mathbf{X}}_{n}+\gamma \ddot{\mathbf{X}}_{n+1}\right)
\end{aligned}
$$


with $\beta$ and $\gamma$ being the Newmark parameters. The subscript $n$ indicates the value of a continuous function at time step $t_{n}$.

However, the unconditional stability is only valid for "smooth" problems like linear elasticity. In our case, due to both element failure and contact conditions, the gain achieved by decreasing the time step can not be as large as in smooth problems. To avoid numerical problems artificial damping is often added like in the HHT- $\alpha$ algorithm [28]. In the following the HHT scheme is used, leading to a modification of Equation (6) which now reads:

$$
\begin{aligned}
\mathbf{M} \ddot{\mathbf{X}}_{n+1}= & (1-\alpha)\left\{\mathbf{F}_{n+1}^{e x t}+\mathbf{F}_{n+1}^{i n t}\right\}+\alpha\left\{\mathbf{F}_{n}^{e x t}+\mathbf{F}_{n}^{i n t}\right\} \\
= & (1-\alpha)\left\{\mathbf{F}_{n+1}^{e x t}+\mathbf{F}_{n+1}^{0}-\mathbf{K}_{n+1} \mathbf{X}_{n+1}-\mathbf{C}_{n+1} \dot{\mathbf{X}}_{n+1}\right\} \\
& +\alpha\left\{\mathbf{F}_{n}^{e x t}+\mathbf{F}_{n}^{0}-\mathbf{K}_{n} \mathbf{X}_{n}-\mathbf{C}_{n} \dot{\mathbf{X}}_{n}\right\}
\end{aligned}
$$

with $\alpha$ being the HHT- $\alpha$ parameter chosen in the range $\left[0, \frac{1}{3}\right]$. Using the classical Newmark updating scheme in Equations (16-17) we get the following system of equations:

$$
\begin{aligned}
& \left\{\mathbf{M}+(1-\alpha)\left(\beta \Delta t^{2} \mathbf{K}_{n+1}+\gamma \Delta t \mathbf{C}_{n+1}\right)\right\} \ddot{\mathbf{X}}_{n+1}= \\
& +\alpha \mathbf{F}_{n}^{i n t}-(1-\alpha) \mathbf{K}_{n+1}\left\{\mathbf{X}_{n}+\Delta t \dot{\mathbf{X}}_{n}+\frac{\Delta t^{2}}{2}(1-2 \beta) \ddot{\mathbf{X}}_{n}\right\} \\
& -(1-\alpha) \mathbf{C}_{n+1}\left\{\dot{\mathbf{X}}_{n}+\Delta t(1-\gamma) \ddot{\mathbf{X}}_{n}\right\}+(1-\alpha) \mathbf{F}_{n+1}^{\text {ext }}+\alpha \mathbf{F}_{n}^{\text {ext }} .
\end{aligned}
$$

This system is usually solved by an iterative algorithm. In our case $\Delta t$ is sufficiently small (due to contact and fracture) for $\mathbf{K}_{n+1}$ and $\mathbf{C}_{n+1}$ to be close to their value at the previous time step. Under this assumption the computation of the new acceleration is straightforward and velocities, displacements and matrices are then updated through Equations (16-17).

\section{EXAMPLE OF COMPUTATIONS}

This section presents some examples of ice failure computations which have been obtained with the model described above. Here we show the capability of the model to capture the behavior of ice qualitatively. To give reliable results, further steps are necessary, including tuning the model parameters against experimental data and analyzing the numerical results in a statistical way.

\subsection{Description of the simulation}

Figure 4 presents a rectangular ice sheet modelled with the lattice described in the previous sections. The size of the sheet is $70 \times 40 \mathrm{~m}^{2}$. The lattice is composed of 6,560 nodes and 9,677 elements. The average length of the springs is $1 \mathrm{~m}$. The velocity is prescribed on the left edge to let the ice sheet impact on a plane rigid structure and then keep crashing against the structure. 


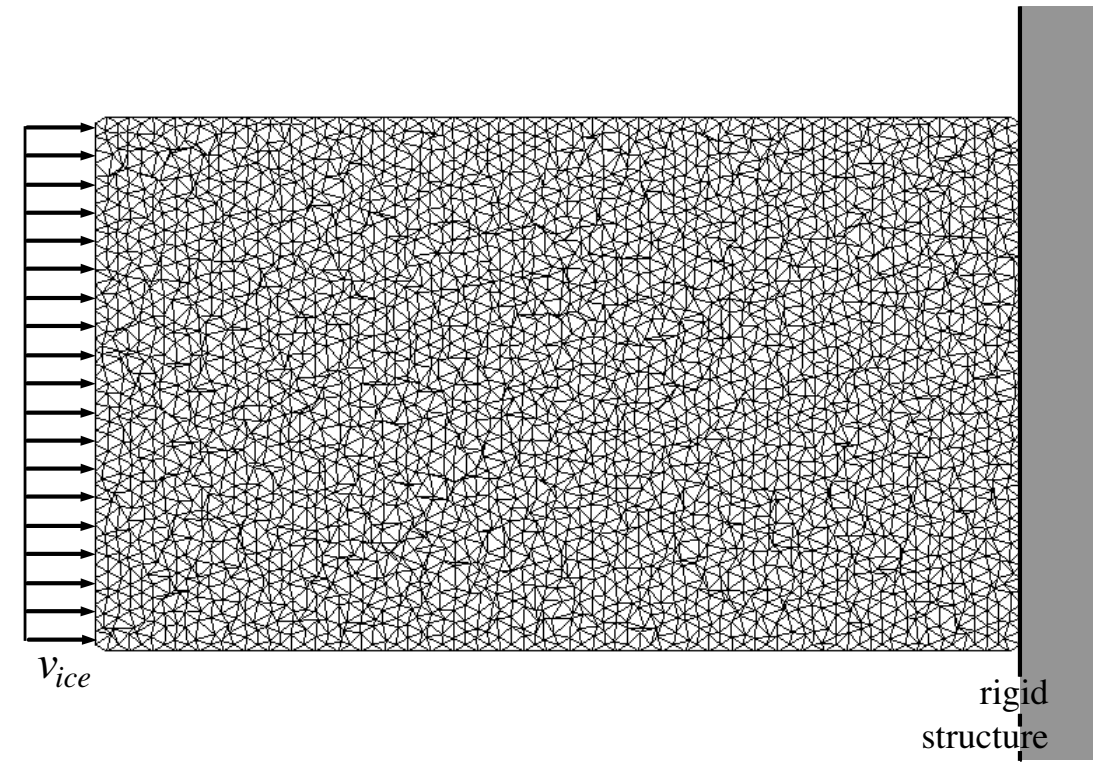

Figure 4: ICE SHEET BEFORE IMPACT WITH THE RIGID STRUCTURE.

We have performed a series of simulations with various prescribed velocities $v_{\text {ice }}$ in the range $[0.1,0.5] \mathrm{m} \mathrm{s}^{-1}$. The direction of the left edge is kept normal to the surface of the structure. The time step $\Delta t$ is chosen according to the material characteristic time such that it is ten times smaller than the critical time $T_{\text {crit }}$, where $T_{\text {crit }}$ satisfies the following relation with the compressive wave velocity in the media:

$$
T_{\text {crit }} \approx h \sqrt{\frac{\rho}{E}}
$$

The lattice properties are summarized in Table 1 . The simulations are ended when the left edge of the ice sheet has moved by $2.5 \mathrm{~m}$.

\subsection{Development of the crack pattern}

Figure 5 shows the force computed with the described lattice model for the ice speed $v_{i c e}=0.1 \mathrm{~m} \mathrm{~s}^{-1}$. The deformed configurations at various time are plotted on Figures 6 to 9.

At the beginning the total contact force increases to a maximum value of about $1.89810^{6} \mathrm{~N}$. Figure 6 shows that this increase is accompanied by failure of several elements inside the ice sheet before reaching the maximum. These broken elements can be referred to as meso-cracks. The locations of the broken elements strongly depend on the distribution of weak elements in the lattice. As the force reaches its maximum one of the meso-cracks becomes a critical one and develops into a macro-crack which can be seen in Figure 7. The complete 


\begin{tabular}{lr}
\hline Young's modulus & $10 \mathrm{MPa}$ \\
Ice density & $920 \mathrm{~kg} \mathrm{~m}^{-3}$ \\
Ice damping & 0.01 \\
Ice-structure friction & 0.02 \\
Ice-ice friction & 0.1 \\
Critical length of element & $1 \%$ \\
Percentage of weak element & $10 \%$ \\
\hline
\end{tabular}

Table 1: MATERIAL PROPERTIES OF THE SIMULATIONS.

\begin{tabular}{ccc}
\hline$v_{\text {ice }}\left(\mathrm{m} \mathrm{s}^{-1}\right)$ & max. force $\left(10^{6} \mathrm{~N}\right)$ & time for max. $(\mathrm{s})$ \\
\hline 0.1 & 1.898 & 3.43 \\
0.2 & 3.122 & 3.38 \\
0.3 & 2.678 & 1.81 \\
0.4 & 2.914 & 1.76 \\
0.5 & 2.670 & 1.71 \\
\hline
\end{tabular}

Table 2: COMPARISONS OF THE RESULTS AT VARIOUS SPEEDS.

failure of the latter, see Figure 8, leads to a major drop in the force between the ice sheet and the structure. After this drop the interaction force stays at a lower level and is essentially governed by friction along the faces of the macro-crack. Figure 9 shows that in this stage secondary cracks are created either by the previously broken elements or by branching from the main damaged zone.

\subsection{Interaction forces with respect to the speed of ice}

Figure 10 shows the contact force for various speeds of ice. As the calculations are ended when the ice sheet has moved by $2.5 \mathrm{~m}$, the calculation time is different for each speed. According to the simulations, the velocity influences the interaction forces in two ways. Firstly, the maximum force is strongly influenced by the velocity. Due to the inertial forces and complex crack patterns the maximum force is obtained with a low, but not the lowest, velocity $v_{i c e}=0.2$ $\mathrm{m} \mathrm{s}^{-1}$. Secondly, the time when the maximum force is reached is also different for the various ice speeds. It is almost the same for the highest velocities $(0.3$ $\mathrm{m} \mathrm{s}^{-1}$ to $0.5 \mathrm{~m} \mathrm{~s}^{-1}$ ), but it changes for $0.1 \mathrm{~m} \mathrm{~s}^{-1}$ and $0.2 \mathrm{~m} \mathrm{~s}^{-1}$. These results are summarized in Table 2.

Finally Figures 9 and 11 to 14 show the damaged ice sheet after crushing for the different velocities. The crack pattern varies with the ice speed. For the highest speeds we get more and more branching in the crack pattern. This has to be further confirmed by experiments, but it shows that a static calculation of these interactions would not be sufficient. 


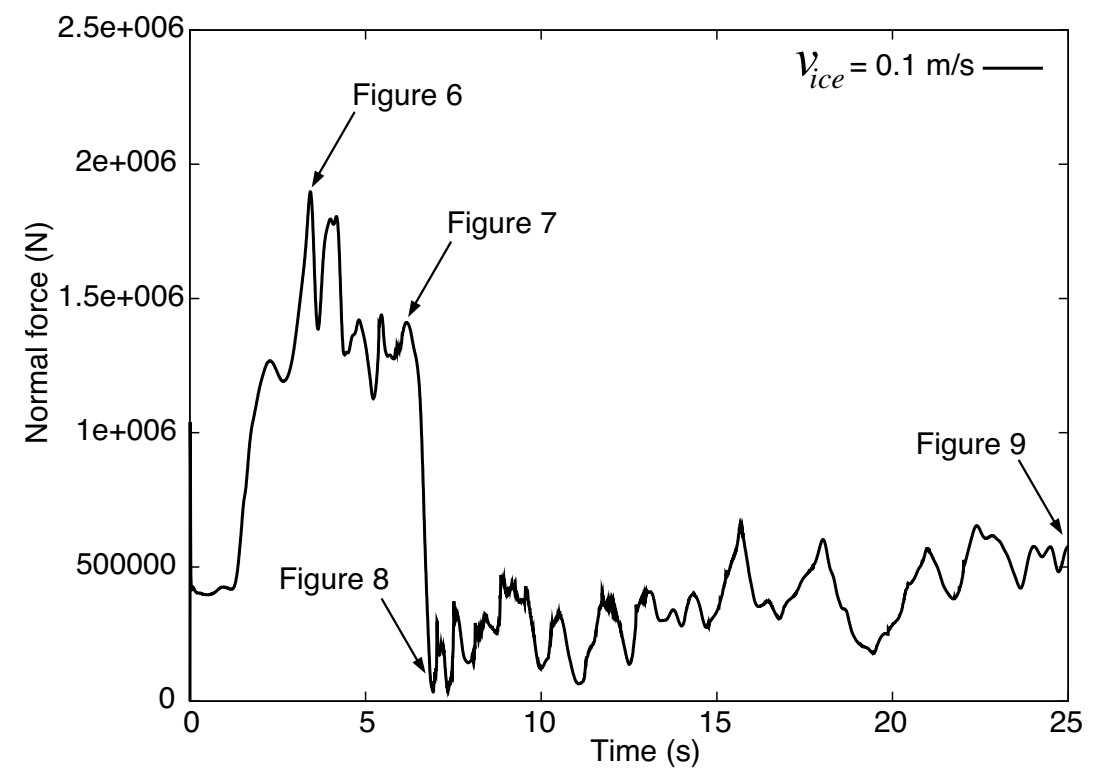

Figure 5: CONTACT FORCE DURING THE CRUSHING AT SPEED $v_{i c e}=$ $0.1 \mathrm{~m} \mathrm{~s}^{-1}$

\section{CONCLUDING REMARKS}

This paper presents a lattice model for the investigation of interaction forces between an ice sheet and a rigid structure. The model seems capable of capturing the ice behavior at a meso-scale, including crack initiation and propagation. These preliminary results are promising but so far they are not sufficient for gaining understanding of the ice-structure interaction. Indeed, further steps must be made to get realistic simulations, including an identification of the model parameters from experimental results, and, after that, a statistical interpretation of the numerical results. These studies are currently undertaken.

\section{Acknowledgement}

Authors wish to gratefully acknowledge support from Shell for this project.

\section{References}

[1] Jordan, I. J., 2001. "Mechanics of ice-structure interaction". Engineering Fracture Mechanics, 68, pp. 1923-1960. 


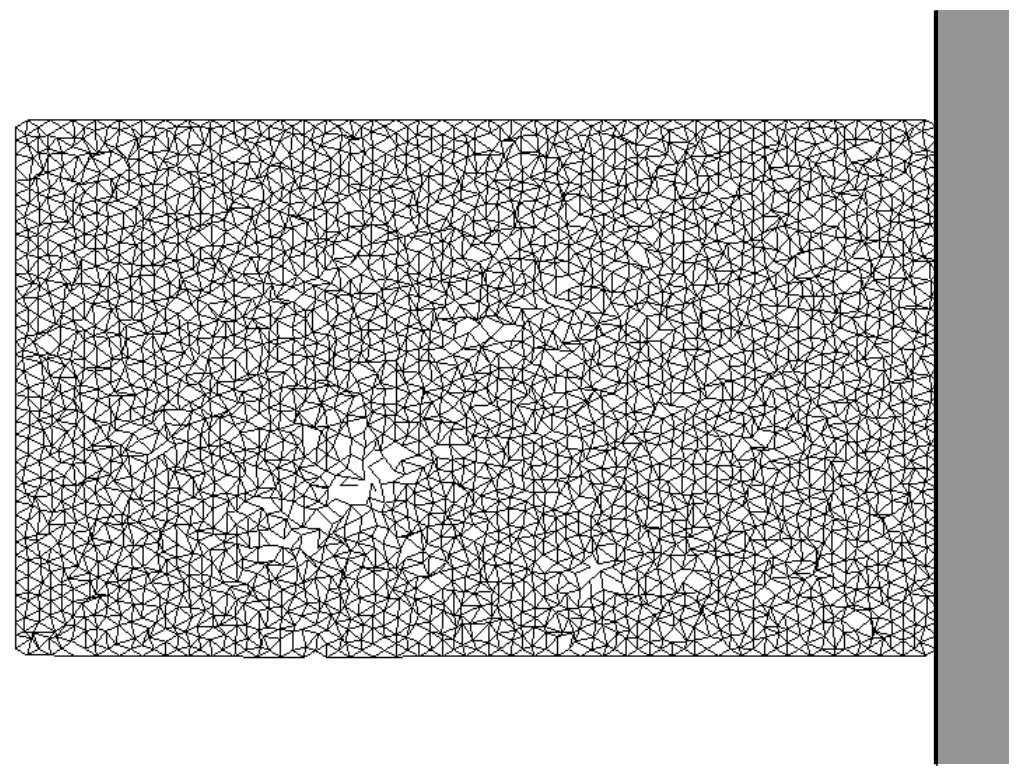

Figure 6: ICE SHEET DAMAGED AFTER CRASHING AGAINST THE STRUCTURE AT SPEED $v_{i c e}=0.1 \mathrm{~m} \mathrm{~s}^{-1}$ AT TIME $t=3.4236 \mathrm{~s}$.

[2] Frederking, R., and Sudom, D., 2006. "Maximum ice force on the Molikpaq during the April 12, 1986 event". Cold Regions Science and Technology, 46, pp. $147-166$.

[3] Bjerkas, M., Skiple, A., and Roe, O. I., 2007. "Applications of continuous wavelet transforms on ice load signals". Engineering Structures, 29(7), pp. $1450-1456$.

[4] Bjerkas, M., 2007. "Review of measured full scale ice loads to fixed structures". In Proc. of the 26th International Conference on Offshore Mechanics and Arctic Engineering (OMAE), ASME Conference.

[5] Sodhi, D. S., 1998. "Nonsimultaneous crushing during edge indentation of freshwater ice sheets". Cold Regions Science and Technology, 27, pp. 179195.

[6] Sohdi, D. S., Takeuchi, T., Nakazawa, N., Akagawa, S., and Saeki, H., 1998. "Medium-scale indentation tests on sea ice at various speeds". Cold Regions Science and Technology, 28, pp. 161-182.

[7] Schulson, E. M., 1999. "The structure and mechanical behavior of ice". J.O.M., 51(2), pp. 21-27.

[8] Kermani, M., Farzaneh, M., and Gagnon, R., 2007. "Compressive strength of atmospheric ice". Cold regions Science and Technology, 49, pp. 195-205. 


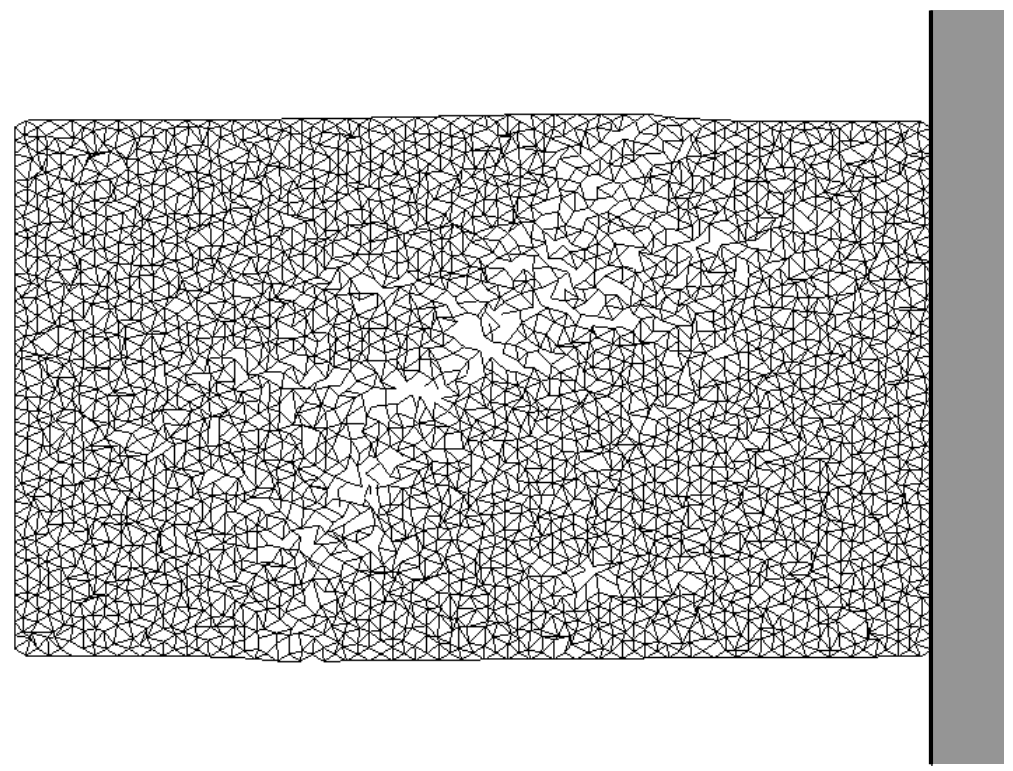

Figure 7: ICE SHEET DAMAGED AFTER CRASHING AGAINST THE STRUCTURE AT SPEED $v_{i c e}=0.1 \mathrm{~m} \mathrm{~s}^{-1}$ AT TIME $t=6.1677 \mathrm{~s}$.

[9] Dempsey, J. P., 2000. "Research trends in ice mechanics". International Journal of Solids and Structures, 37, pp. 131-153.

[10] Daley, C., Tuhkuri, J., and Riska, K., 1998. "The role of discrete failures in local ice loads". Cold Regions Science and Technology, 27, pp. 197-211.

[11] Kamio, Z., Matsushita, H., and Strnadel, B., 2003. "Statistical analysis of ice fracture characteristics". Engineering Fracture Mechanics, 70, pp. 2075-2088.

[12] Kärna, T., Qu, B., Bi, X., Yue, Q., and Kuehnlein, W., 2007. "A spectral model for forces due to ice crushing". Journal of Offshore Mechanics and Arctic Engineering, 129(2), pp. 138-145.

[13] Ostoja-Starzewski, M., Sheng, P. Y., and Alzebdeh, K., 1996. "Spring network models in elasticity and fracture of composites and polycrystals". Computational Materials Science, 7, pp. 82-93.

[14] Schlangen, E., and Garboczi, E. J., 1996. "New method for simulating fracture using an elastically uniform random geometry lattice". Int. J. Engng. Sci., 34(10), pp. 1131-1144.

[15] Chiaia, B., Vervuurt, A., and Van Mier, J. G. M., 1997. "Lattice model evaluation of progressive failure in disordered particle composites". Engineering Fracture Mechanics, 57(2/3), pp. 301-318. 


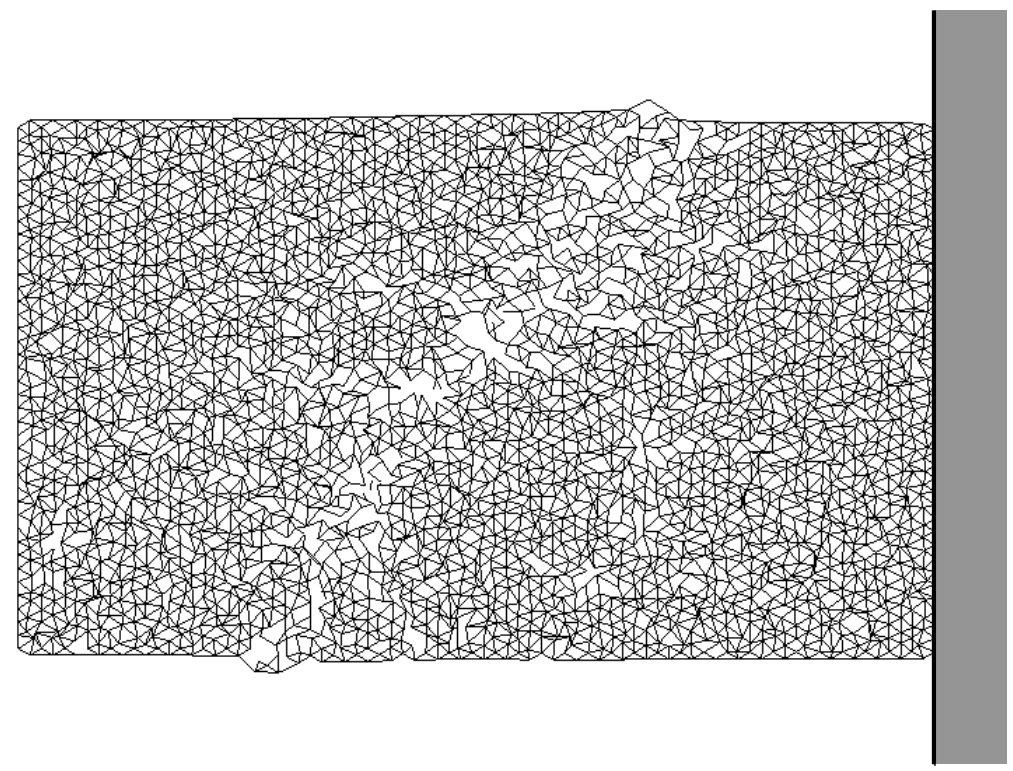

Figure 8: ICE SHEET DAMAGED AFTER CRASHING AGAINST THE STRUCTURE AT SPEED $v_{i c e}=0.1 \mathrm{~m} \mathrm{~s}^{-1}$ AT TIME $t=6.8994 \mathrm{~s}$.

[16] Schlangen, E., and Garboczi, E. J., 1997. "Fracture simulations of concrete using lattice models: computational aspects". Engineering Fracture Mechanics, 57(2/3), pp. 319-332.

[17] Van Mier, J. G. M., Van Vliet, M. R. A., and Wang, T. K., 2002. "Fracture mechanisms in particle composites: statistical aspects in lattice type analysis". Mechanics of Materials, 34, pp. 705-724.

[18] Karihaloo, B. L., Shao, P. F., and Xiao, Q. Z., 2003. "Lattice modelling of the failure of particle composites". Engineering Fracture Mechanics, 70, pp. 2385-2406.

[19] Ibrahimbegovic, A., and Delaplace, A., 2003. "Microscale and mesoscale discrete models for dynamic fracture of structures built of brittle material". Computers \& Structures, 81, pp. 1255-1265.

[20] Hou, P., 2007. "Lattice model applied to the fracture of large strain composite". Theoretical and Applied Fracture Mechanics, 47, pp. 233-243.

[21] Sayed, M., and Timco, G. W., 1999. "A lattice model of ice failure". In Proc. of the 9th International Offshore and Polar Engineering Conference, Vol. II, pp. 528-534. 


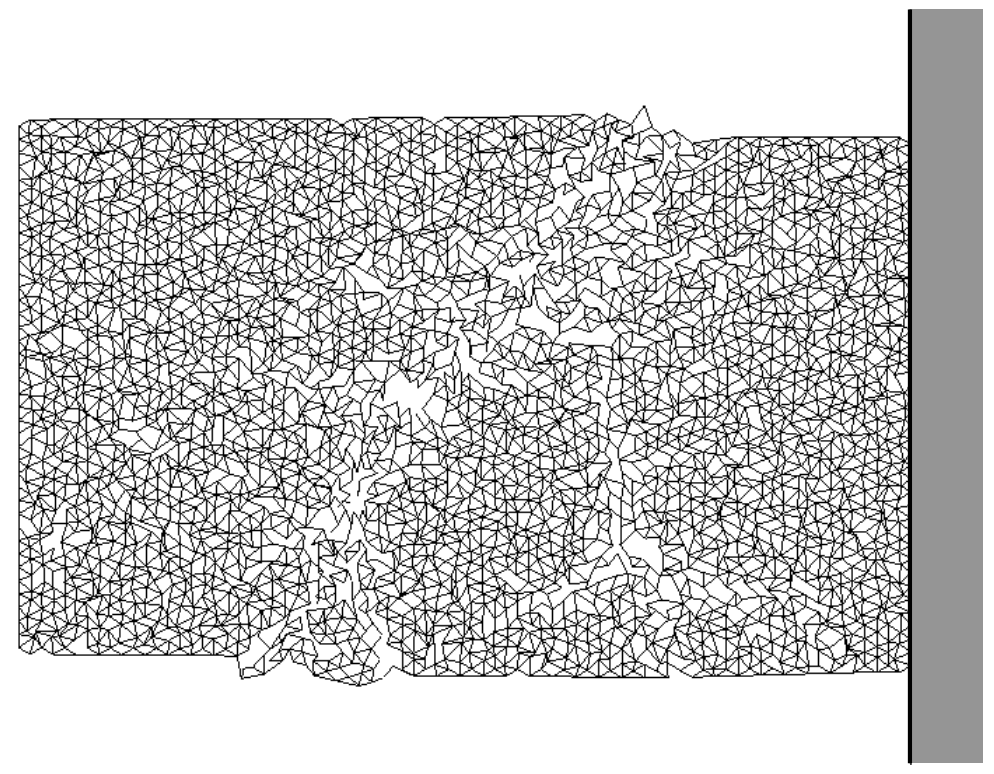

Figure 9: ICE SHEET DAMAGED AFTER CRASHING AGAINST THE STRUCTURE AT SPEED $v_{i c e}=0.1 \mathrm{~m} \mathrm{~s}^{-1}$ AT TIME $t=25 \mathrm{~s}$.

[22] Selvadurai, A. P. S., and Sepehr, K., 1999. "Two-dimensional discrete element simulations of ice-structure interaction". International Journal of Solids and Structures, 36, pp. 4919-4940.

[23] Alart, P., and Curnier, A., 1991. "A mixed formulation for frictional contact problems prone to Newton like solution methods". Comput. Methods Appl. Mech. Engrg., 92, pp. 353-375.

[24] Simo, J. C., and Laursen, T. A., 1992. "An augmented lagrangian treatment of contact problems involving friction". Computers \& Structures, 42(1), pp. 97-116.

[25] Wriggers, P., 1996. "Finite element methods for contact problems with friction". Tribology International, 29(8), pp. 651-658.

[26] Fortin, J., Hjiaj, M., and De Saxcé, G., 2002. "An improved discrete element method based on a variational formulation of the frictional contact law". Computers and Geotechnics, 29, pp. 609-640.

[27] Wriggers, P., 2002. Computational Contact Mechanics. J. Wiley \& Sons, New York.

[28] Hilbert, H. M., Hugues, T. J. R., and Taylor, R. L., 1977. "Improved numerical dissipation for time integration algorithms in structural dynamics". 


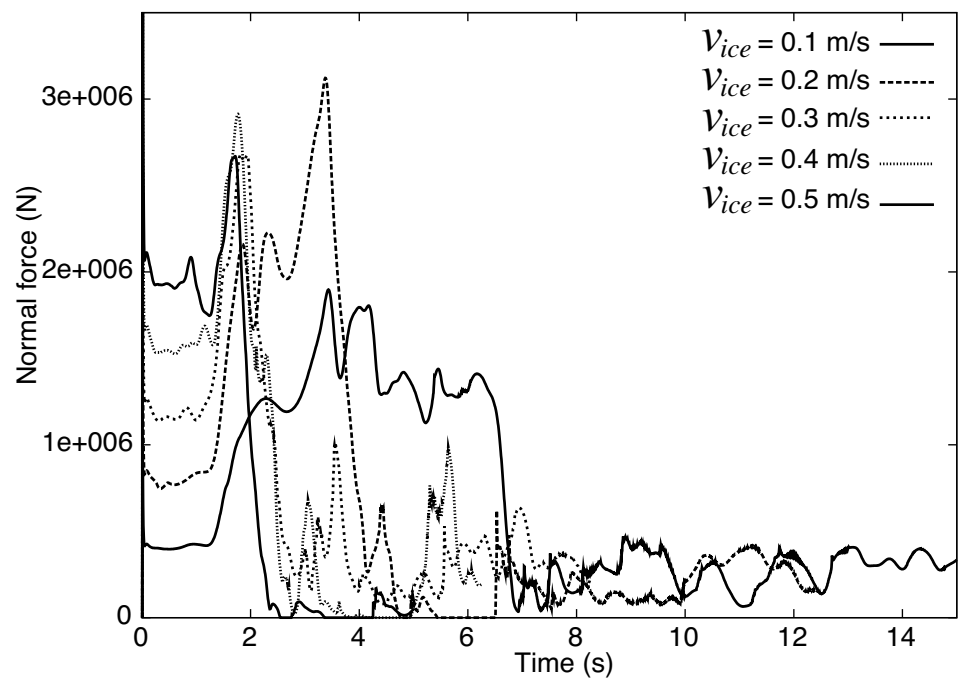

Figure 10: CONTACT FORCE DURING THE CRUSHING AT VARIOUS SPEEDS.

International Journal for Earthquake Engineering and Structural Dynamics, 5, pp. 283-292. 


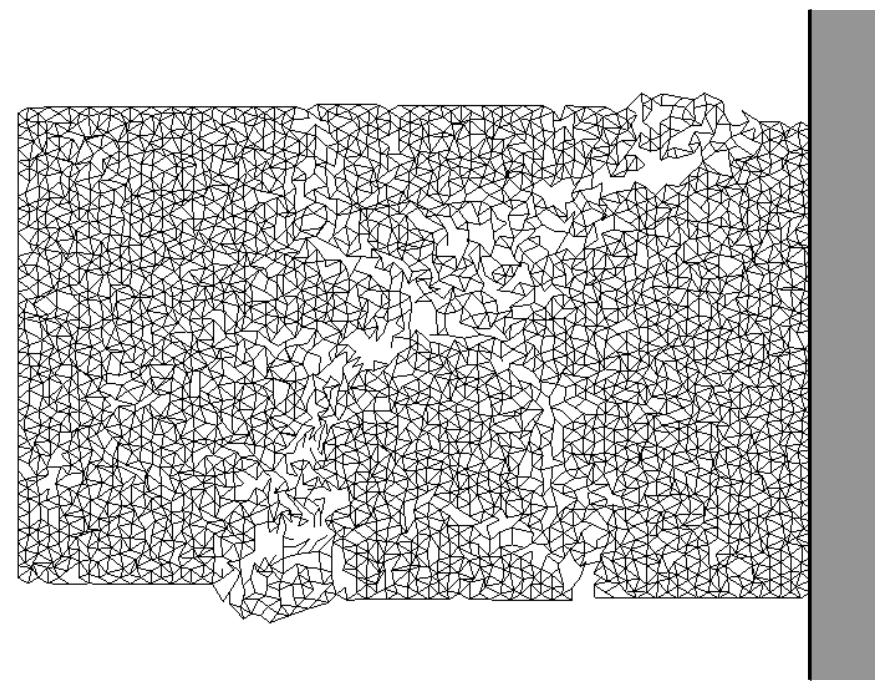

Figure 11: ICE SHEET DAMAGED AFTER CRASHING AGAINST THE STRUCTURE AT SPEED $v_{\text {ice }}=0.2 \mathrm{~m} \mathrm{~s}^{-1}$ AT TIME $t=20 \mathrm{~s}$.

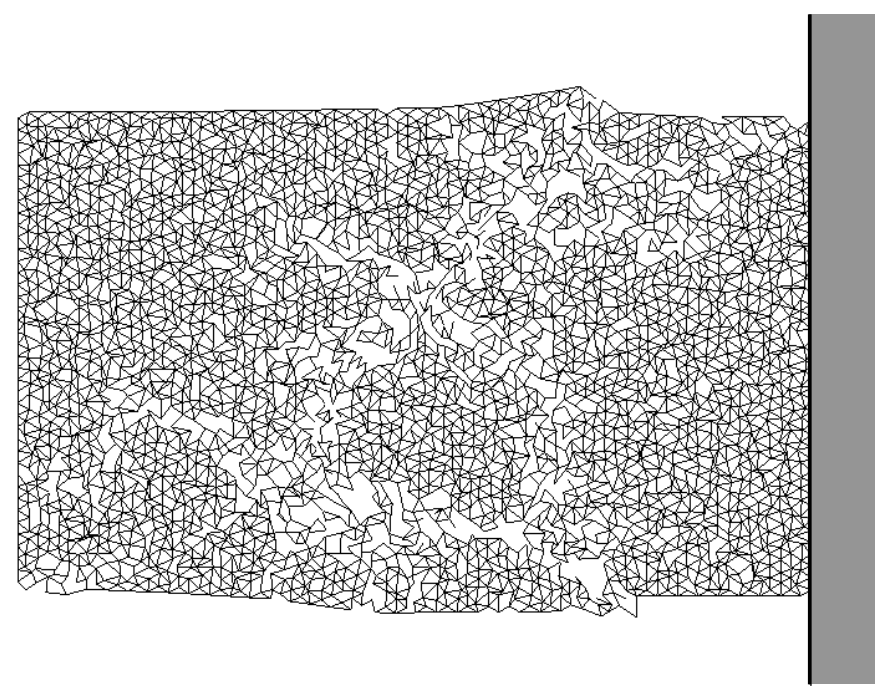

Figure 12: ICE SHEET DAMAGED AFTER CRASHING AGAINST THE STRUCTURE AT SPEED $v_{i c e}=0.3 \mathrm{~m} \mathrm{~s}^{-1}$ AT TIME $t=15 \mathrm{~s}$. 


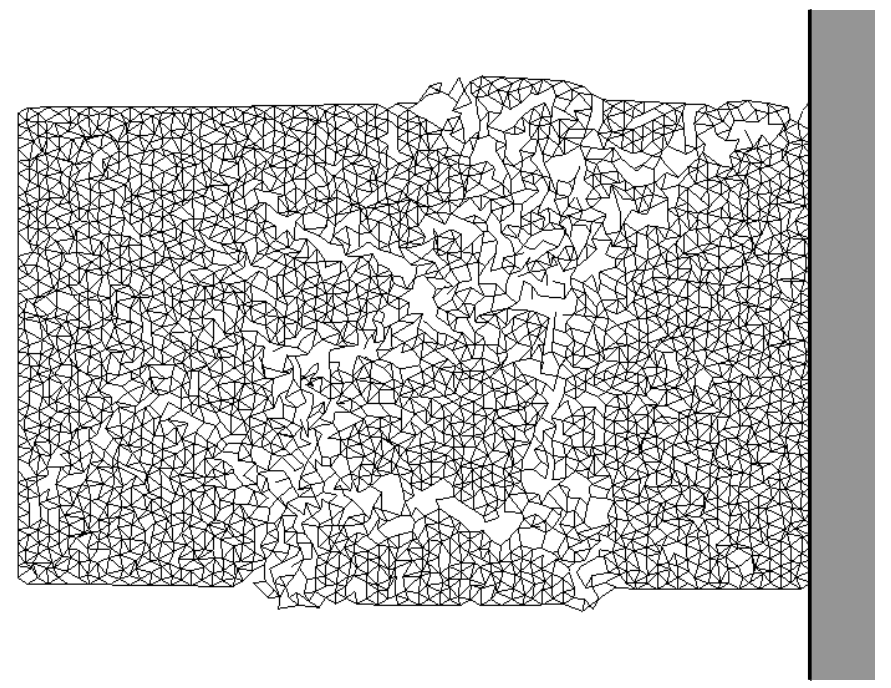

Figure 13: ICE SHEET DAMAGED AFTER CRASHING AGAINST THE STRUCTURE AT SPEED $v_{i c e}=0.4 \mathrm{~m} \mathrm{~s}^{-1}$ AT TIME $t=10 \mathrm{~s}$.

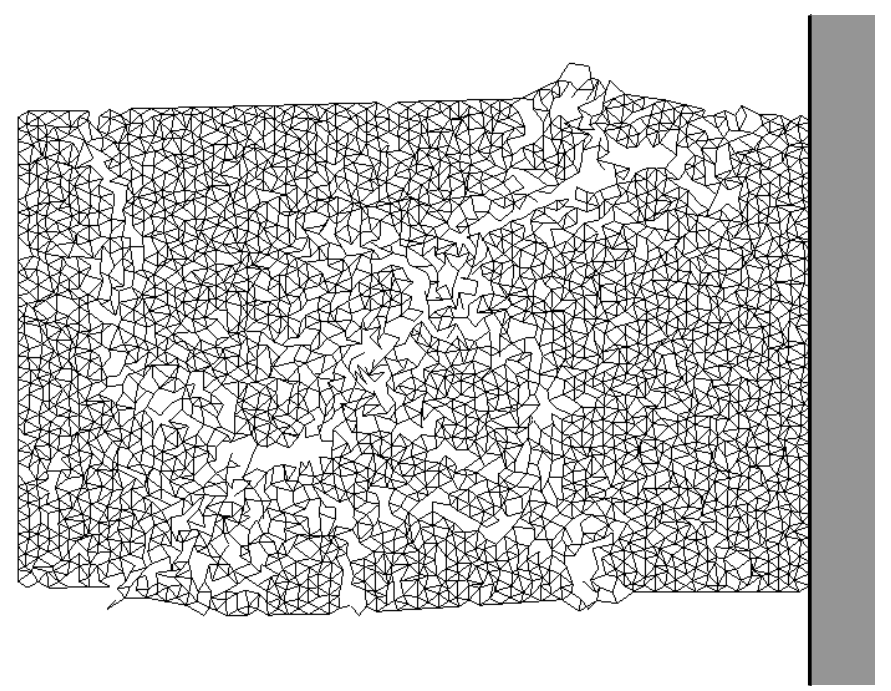

Figure 14: ICE SHEET DAMAGED AFTER CRASHING AGAINST THE STRUCTURE AT SPEED $v_{i c e}=0.5 \mathrm{~m} \mathrm{~s}^{-1}$ AT TIME $t=5 \mathrm{~s}$. 